\title{
The energetic costs of mounting an immune response for Pallas's long-tongued bat (Glossophaga soricina)
}

\author{
Lucia V. Cabrera-Martinez ${ }^{1}$ ， L. Gerardo Herrera M. ${ }^{\text {Corresp., }}{ }^{2}$ ， Ariovaldo P. Cruz-Neto ${ }^{1}$ \\ ${ }^{1}$ Departamento de Zoologia, Instituto de Biociências, Universidade Estadual Paulista Júlio de Mesquita Filho, Rio Claro, São Paulo, Brasil \\ 2 Estacion de Biologia Chamela, Instituto de Biología, Universidad Nacional Autónoma de México, San Patricio, Jalisco, México \\ Corresponding Author: L. Gerardo Herrera M. \\ Email address: gherrera@ib.unam.mx
}

The acute phase response (APR) is the first line of defense of the vertebrate immune system against pathogens. Mounting an immune response is believed to be energetically costly but direct measures of metabolic rate during immune challenges contradict this assumption. The energetic cost of APR for birds is higher than for rodents suggesting that this response is less expensive for mammals. However, the particularly large increase in metabolic rate after APR activation for a piscivorous bat (Myotis vivesi) suggests that immune response might be unusually costly for bats. Here we quantified the energetic cost and body mass change associated with APR for the nectarivorous Pallas's long-tongued bat (Glossophaga soricina). Activation of the APR resulted in a short-term decrease in body mass and an increase in resting metabolic rate (RMR) with a total energy cost of only $2 \%$ of the total energy expenditure estimated for $G$. soricina. This increase in RMR was far from the large increase measured for piscivorous bats; rather, it was similar to the highest values reported for birds. Overall our results suggest that the costs of APR for bats may vary interspecifically. Measurement of the energy cost of vertebrate immune response is limited to a few species and further work is warranted to evaluate its significance for an animal's energy budget. 
The energetic costs of mounting an immune response for Pallas's long-tongued bat (Glossophaga soricina)

Lucía V. Cabrera-Martinez ${ }^{1}$, L. Gerardo Herrera M. ${ }^{2}$, Ariovaldo P. Cruz-Neto ${ }^{1}$

${ }^{1}$ Departamento de Zoologia, Instituto de Biociências, Universidade Estadual Paulista Júlio de Mesquita Filho, Rio Claro, São Paulo, Brasil.

${ }^{2}$ Estación de Biología Chamela, Instituto de Biología, Universidad Nacional Autónoma de México, San Patricio, Jalisco, México.

Corresponding author:

L. Gerardo Herrera M.

Email address: gherrera@ib.unam.mx 


\section{Abstract}

2 The acute phase response (APR) is the first line of defense of the vertebrate immune system

3 against pathogens. Mounting an immune response is believed to be energetically costly but direct

4 measures of metabolic rate during immune challenges contradict this assumption. The energetic

5 cost of APR for birds is higher than for rodents suggesting that this response is less expensive for

6 mammals. However, the particularly large increase in metabolic rate after APR activation for a

7 piscivorous bat (Myotis vivesi) suggests that immune response might be unusually costly for bats.

8 Here we quantified the energetic cost and body mass change associated with APR for the

9 nectarivorous Pallas's long-tongued bat (Glossophaga soricina). Activation of the APR resulted

10 in a short-term decrease in body mass and an increase in resting metabolic rate (RMR) with a

11 total energy cost of only $2 \%$ of the total energy expenditure estimated for G. soricina. This

12 increase in RMR was far from the large increase measured for piscivorous bats; rather, it was

13 similar to the highest values reported for birds. Overall our results suggest that the costs of APR

14 for bats may vary interspecifically. Measurement of the energy cost of vertebrate immune

15 response is limited to a few species and further work is warranted to evaluate its significance for

16 an animal's energy budget. 


\section{Introduction}

19 Mounting an immune response is believed to be energetically costly requiring trade-offs with other important biological functions (Sheldon \& Verhulst, 1996). The energy cost of immune response activation by vertebrates, for example, has been hypothesized to equal that of reproduction and growth (Lochmiller \& Deerenberg, 2000). The acute phase response (APR), in particular, is believed to be the most energetically costly component of the activation of the immune system and so, more prone to trade-off with other energetically expensive life-history traits (Lochmiller \& Deerenberg, 2000; Bonneaud et al., 2003; Lee, 2006; but see King \& Swanson, 2013). The APR, thought to be taxonomically conserved amongst vertebrates, is the first line of defense of the immune system against pathogens and involves leukocytosis, fever, increased resting metabolic rate $(\mathrm{RMR})$ and decreased body mass $\left(\mathrm{M}_{\mathrm{b}}\right)(\mathrm{Cray}$, Zaias \& Altman, 2009). However, direct measures of metabolic rate challenge the idea that an immune response is an energetically costly process. For example, RMR of several bird species increased only 5-15\%

31 following activation of humoral and cell-mediated immunities (Hasselquist \& Nilsson, 2012). One method used to trigger APR in vertebrates is the use of a lipopolysaccharide (LPS; Alexander \& Rietschel, 2001). This antigen mimics a bacterial infection without actually infecting an animal with a pathogen. LPS induces an inflammatory response by increasing the release of cytokines a few hours after inoculation causing a short-term response (Bonneaud et al., 2003; Demas et al., 2011). The metabolic cost of this short-term (within 24 hours after LPS injection) APR has been measured for a handful of species with contrasting results. APR activation resulted in a large increase (185\%) in RMR for fish-eating Myotis (Myotis vivesi;

39 Otálora-Ardila et al., 2016, 2017), a modest increase ( 26-40\%) for Pekin ducks (Anas 40 platyrhynchos; Marais, Maloney \& Gray, 2011) and house sparrows (Passer domesticus; King \& 
41 Swanson, 2013; Martin et al., 2017), a small increase ( 10-14\%) for zebra finches (Taeniopygia

42 guttata; Burness, Armstrong \& Tilman-Schindel, 2010), house sparrows (Martin et al., 2017) and

43 the brown rat (Rattus norvegicus; MacDonald et al., 2012), and null increase for zebra finches

44 (Sköld-Chiriac et al., 2014), house sparrows (Martin et al., 2017) and house mice (Mus

45 musculus; Baze, Hunter \& Hayes, 2011). These studies involved both captive-raised (Burness,

46 Armstrong \& Tilman-Schindel, 2010; Baze, Hunter \& Hayes, 2011; Marais, Maloney \& Gray,

47 2011; Sköld-Chiriac et al., 2014) and wild populations (King \& Swanson 2013, Otálora-Ardila et

48 al. 2016, 2017, Martin et al., 2017)

49 A strong immune response is assumed to be more likely for long-lived animals

50 (Lochmiller \& Deerenberg, 2000), such as bats. Bats are one of the most diverse orders of

51 vertebrates both in taxonomic and ecological terms and thus represent an exceptional model to

52 test if APR is an energetically costly event. Although bats may share several features of the

53 immune systems with other vertebrates, they do have marked qualitative and quantitative

54 differences in their immune system (Baker, Schountz \& Wang, 2013). Evidence suggests that the

55 magnitude of their immune response may vary as a function of body mass and physiological and

56 ecological factors (Christe, Arlettaz \& Vogel, 2000; Allen et al., 2009; Schneeberger, Czirják \&

57 Voigt, 2013b; Schneeberger, Czirják \& Voigt, 2014; Strobel, Becker \& Encarnação, 2015). For

58 example, APR triggered an increase in total leukocyte numbers and a decrease in $\mathrm{M}_{\mathrm{b}}$ for the

59 short-tailed fruit bat (Carollia perspicillata; Schneeberger, Czirják \& Voigt, 2013a) and an

60 increase in total leukocyte and neutrophill numbers and no change in $\mathrm{M}_{\mathrm{b}}$ for the wrinkle-lipped

61 bat (Chaerephon plicatus; Weise et al., 2017). APR induced a significant decrease in $\mathrm{M}_{\mathrm{b}}$ and an

62 increase in body temperature $\left(\mathrm{T}_{\mathrm{b}}\right)$ for the fish-eating Myotis (Otálora-Ardila et al., 2016, 2017),

63 whereas for the Pallas's mastiff bat (Molossus molossus) there was a reduction in $\mathrm{M}_{\mathrm{b}}$ but no 
64 change in total leukocyte numbers or $\mathrm{T}_{\mathrm{b}}$ (Stockmaier et al., 2015). The large increase in RMR

65 that accompanied the immune response of the fish-eating Myotis (Otálora-Ardila et al., 2016,

66 2017) is unusual among vertebrates but there is no available information to evaluate if this

67 elevated RMR is common to bats. Alternatively, and consistent with the responses reported for

68 other aspects of bat APR, the metabolic cost of this response might vary within the order

69 Chiroptera.

$70 \quad$ Here, we measure RMR and $\mathrm{M}_{\mathrm{b}}$ of the nectarivorous Pallas's long-tongued bat

71 (Glossophaga soricina, Pallas 1766; Phyllostomidae) before and after challenging its immune

72 system with an injection of LPS. We aimed to quantify and describe the magnitude of the

73 energetic costs associated with APR for this plant-eating bat. We compared the effect of the APR

74 on $\mathrm{RMR}$ and $\mathrm{M}_{\mathrm{b}}$ for $G$. soricina with that for the fish-eating Myotis and other vertebrates to test

75 the hypothesis that activation of this immune response is unusually costly for bats. We are aware

76 that our comparison is limited by the variety of protocols used in previous measurements of APR

77 activation in vertebrates and we are therefore cautious to consider it in a qualitative framework.

78 Materials \& Methods

79 Animal capture and housing

80 Adult non-reproductive individuals of $G$. soricina (9 males and 4 females; $\mathrm{M}_{\mathrm{b}}=10.3 \pm 0.3 \mathrm{~g}$,

81 mean \pm 1 S.E. here and thereafter) were captured with mist nets during late spring at the entrance

82 of the El Salitre cave, $3.6 \mathrm{~km}$ South of Los Ortices $\left(19^{\circ} 04^{\prime} \mathrm{N}, 103^{\circ} 43^{\prime} \mathrm{W}\right)$, Colima, Mexico.

83 Three to four individuals were captured during each visit to the cave, and kept in a $3 \times 3 \times 3 \mathrm{~m}$

84 flight cage in a nearby facility with natural photoperiod and temperature. They were fed a

85 mixture of cereal, table sugar, powdered milk and banana diluted with water. Experiments

86 commenced 2-3 days after capture and, once measurements were complete, bats were released at 
87 the site of capture. Each bat was measured only once and held in captivity for $\leq 5$ days. We

88 followed the American Society of Mammologists animal guidelines (Sikes, Gannon \& The

89 Animal Care and Use Commitee of the American Society of Mammalogists, 2011), and all

90 protocols were performed under a scientific's collector license (FAUT-0069) granted to LGHM

91 by the Secretaría de Medio Ambiente y Recursos Naturales, Mexico.

92 Immune challenge

93 We challenged the immune system of bats (7 individuals) by injecting $50 \mu \mathrm{L}$ of a 0.56

$94 \mathrm{mg} \mathrm{ml}^{-1}$ solution of LPS (L2630, Sigma-Aldrich, USA) in phosphate buffered saline (PBS;

95 P4417, Sigma-Aldrich, USA). This is equivalent to a dose of $2.84 \pm 0.04 \mathrm{mg} \mathrm{LPS} \mathrm{kg}{ }^{-1}$. LPS was

96 injected subcutaneously and the surrounding skin was sterilized with ethanol prior to and after

97 the injection. Pilot experiments indicated that this dose was sufficiently high to elicit a sustained

98 and significant response in RMR; lower doses did not cause a measurable response and higher

99 doses elicited a blunted response. A control group of 6 individuals was injected with only PBS.

100 Metabolic measurements

101 The energetic cost associated with mounting an immune response was indirectly assessed

102 by measuring the rates of oxygen consumption $\left(\mathrm{VO}_{2}\right)$ for individuals in post-absorptive state

103 prior to and after receiving LPS or PBS. Experiments started at 06:00-07:00 am, with

104 measurements of pre-injection levels for two hours, and one individual bat per trial. Pilot

105 experiments indicated that bats usually settled down in the chamber after 1 hour, so this period

106 was considered sufficient for RMR to achieve a steady-state that could be used as standard for

107 comparing the incremental responses associated with the administration of LPS or PBS (see

108 results). After this period, we removed the bat from the respirometric chamber, injected it with

109 either LPS or PBS, and returned it to the chamber, after which $\mathrm{VO}_{2}$ was continuously measured 
110 for 8-10 hours. The time required to remove the bat from the chamber, inject it and return it the

111 chamber was less than five minutes.

112 We used open-flow respirometry to measure $\mathrm{VO}_{2}$ (Voigt and Cruz-Neto 2009). Bats were

113 weighed to the nearest $0.1 \mathrm{~g}$ (Ohaus Precision Balance, USA), and placed in a $300 \mathrm{ml}$ cylindrical

114 metabolic chamber. Because the chamber walls were made of smooth material, bats could hang

115 only from plastic mesh placed at the top. A similar-sized, but empty, chamber was used for

116 baseline measurements. Incurrent air, dried with a column of Drierite ${ }^{\mathrm{TM}}$ (W. A. Hammond

117 Drierite, Xenia, Ohio, USA) was pushed through both chambers by two sets of aquarium pumps

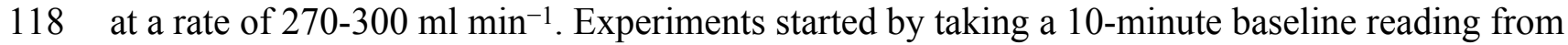

119 the empty chamber and then 2 continuous 60-minute readings of the excurrent air from the

120 experimental chamber, interspaced by a 10-minute baseline reading between each run. Excurrent

121 air was passed through a column of Drierite ${ }^{\mathrm{TM}}$ then through an $\mathrm{O}_{2}$ analyzer (Sable System Field

122 Metabolic System, Sable Systems International, Las Vegas, USA). Bats were removed from the

123 chamber, injected with either PBS or LPS, and returned to the chamber. We then recommenced

124 recording $\mathrm{VO}_{2}$ with continuous readings from the experimental chamber, interspaced by 10 -

125 minutes reading of the empty chamber at every hour.

126 Excurrent $\mathrm{O}_{2}$ values were recorded every second, and these data subsequently analyzed

127 by the software Expedata 1.7.2 (Sable Systems International). Readings from the $\mathrm{O}_{2}$ channels

128 were smoothed before the analysis, and $\mathrm{VO}_{2}$ were calculated using equation 10.2 from Lighton

129 (2008). We calibrated the $\mathrm{O}_{2}$ sensors every second day by flowing with a $20.95 \% \mathrm{O}_{2}$ gas mix

130 from a commercial compressed gas supplier (Praxair, Danbury, CT, USA).

131 The temperature $\left(\mathrm{T}_{\mathrm{a}}\right)$ within the chambers was measured every 30 minutes with a

132 temperature logger placed in the bottom of the chamber (I-button, Maxim Corp, San Jose, USA). 
$133 \mathrm{~T}_{\mathrm{a}}$ was $28.9 \pm 0.1^{\circ} \mathrm{C}$, with a minimum-maximum variation of $2.1 \pm 0.1^{\circ} \mathrm{C}$, during the

134 experiments. The mean value was slightly below the lower critical limit of the thermoneutral

135 zone described for our focal species $\left(31.4^{\circ} \mathrm{C}\right.$; Cruz-Neto \& Abe, 1997), and the maximum $\mathrm{T}_{\mathrm{a}}$

136 attained during a given experiment $\left(32.6^{\circ} \mathrm{C}\right)$ was below its upper critical temperature $\left(35.2^{\circ} \mathrm{C}\right.$;

137 Cruz-Neto \& Abe, 1997).

138 Data handling and analysis

139 Due to the small sample size for females ( 2 in each treatment group), data from both

140 sexes were pooled. $\mathrm{M}_{\mathrm{b}}$ was measured within 10 minutes of injection of LPS or PBS ( $\left.\mathrm{M}_{\mathrm{bi}}\right)$ and

141 again after the last $\mathrm{VO}_{2}$ measurement $\left(\mathrm{M}_{\mathrm{bf}}\right)$. Differences in mean $\mathrm{M}_{\mathrm{b}}$, as well as in absolute $\left(\mathrm{M}_{\mathrm{bf}}\right.$

$\left.142-\mathrm{M}_{\mathrm{bi}}\right)$ and relative $\left[\left(\mathrm{M}_{\mathrm{bf}}-\mathrm{M}_{\mathrm{bi}} / \mathrm{M}_{\mathrm{bi}}\right)\right]$ changes between groups were analyzed by t-tests.

143 Activity of the bats inside the chamber caused $\mathrm{O}_{2}$ levels to fluctuate during experiments.

144 To minimize such fluctuations, we used the nadir function (Expedata 1.7.2; Sable Systems

145 International), which calculates the lowest-magnitude section of a specified number of

146 contiguous data to select the lowest and most constant 15 minute period of $\mathrm{VO}_{2}$ for each hour of

147 the experiment, and then an average of these 15 minute periods was used to characterize the $\mathrm{VO}_{2}$

148 for each hour time bin. These values were transformed to metabolic rate (MR) in $\mathrm{kJ} \mathrm{h}^{-1}$, by using

149 the formula provided by Lighton (2008): $\mathrm{MR}=\mathrm{VO}_{2} \times[16+5.164(\mathrm{RQ})]$. Since we did not

150 measure $\mathrm{VCO}_{2}$, we assumed an RQ of 0.80, and used the RMR values in all subsequent analyses.

151 We used this RQ because it is the value measured for G. soricina in post-absorptive state

152 (Welch, Herrera \& Suarez. 2008).

153 We used a generalized linear mixed effect model to test if $\mathrm{T}_{\mathrm{a}}$ varied with time and

154 treatment. Although different individuals were used in the PBS and LPS treatments, we had

155 repeated measurements of $\mathrm{T}_{\mathrm{a}}$ over time for each treatment. Thus, we included bat ID as a random 
156 factor in these analyses. We tested the effects of time and treatment on RMR with similar

157 generalized linear mixed effect models before and after the injection. For the RMR data obtained

158 after the injection, we used net values of mass-specific RMR obtained by subtracting the lowest

159 mass-specific RMR value before the injection from the post-injection mass-specific RMR for

160 each individual at each time bin. Pairwise comparisons were made using a Holm-Sidak post-hoc

161 test when the model identified significant differences.

162 We calculated an energetic cost index (EC) for responses to LPS and PBS to estimate

163 the energetic costs associated with APR activation. EC is equal to the integral area under the

164 curve that describes the variation in net mass-specific RMR after injection for each treatment.

165 We calculated the area under the curve using the trapezoid method (Tai 1994). Mass-corrected

166 EC estimated for each treatment were compared to zero using one-sample t-tests, and the effect

167 of $\mathrm{T}_{\mathrm{a}}$ on $\mathrm{EC}$ was assessed by simple linear regression for each treatment. We set the level of

168 significance to $p \leq 0.05$ for all statistical analyses. Data analyses were performed using

169 SigmaStat ver. 4 (Systat Sofware Inc., San Jose, USA) and statistiXL ver 2.0 (statistiXL,

170 Broadway-Nedlands, Australia).

\section{Results}

172 Body mass changes

173 The $\mathrm{M}_{\mathrm{bi}}$ of $G$. soricina did not vary between treatments $\left(\mathrm{t}_{11}=0.63, p=0.54\right.$; Table 1$)$, but

$174 \mathrm{M}_{\mathrm{bf}} \operatorname{did}\left(\mathrm{t}_{11}=2.92, p=0.03\right)$. Bats injected with LPS lost more body mass than bats injected

175 with PBS, both in absolute (PBS: $-0.6 \pm 0.11 \mathrm{~g}$, LPS: $-1.15 \pm 0.14 \mathrm{~g} ; \mathrm{t}_{11}=3.05, p=0.01$ ) and in

176 relative (PBS: $-0.06 \pm 0.01$, LPS: $\left.-0.11 \pm 0.01 ; \mathrm{t}_{11}=3.70, p=0.004\right)$ terms.

\section{Metabolic Rate}

$178 \mathrm{~T}_{\mathrm{a}}$ varied with time $\left(\mathrm{F}_{9,129}=4.94 ; p<0.001\right)$. However, it did not differ between 
179 treatments (LPS: $28.9 \pm 0.1^{\circ} \mathrm{C}$; PBS: $29.0 \pm 0.1^{\circ} \mathrm{C}: \mathrm{F}_{1,129}=2.75 ; p=0.1$ ) or as a function of the

180 interaction between time and treatment $\left(\mathrm{F}_{9,129}=4.94 ; p=0.91\right)$. Therefore, we assumed that $\mathrm{T}_{\mathrm{a}}$

181 measured during the experiments was not a confounding factor.

182 Metabolic rate measured prior to injection varied with time $\left(\mathrm{F}_{1,23}=61.9, p<0.001\right.$; Fig

183 1), with the lowest value for both groups recorded 1 hour before injection. This value did not

184 differ between the two treatment groups (PBS: $0.031 \pm 0.005 \mathrm{~kJ} \mathrm{~h}^{-1} \mathrm{~g}^{-1}$; LPS: $0.036 \pm 0.005 \mathrm{~kJ} \mathrm{~h}^{-1}$

$\left.185 \mathrm{~g}^{-1} ; \mathrm{F}_{1,23}=0.14, p=0.71\right)$, and there was no significant treatment by time effect on pre-injection

$186 \operatorname{RMR}\left(\mathrm{F}_{1,23}=0.55, p=0.58\right)$. Thus, we used the RMR values obtained 1 hour before the

187 injection as our standard for calculating the net RMR after injection.

188 After injection, the net RMR varied significantly as a function of time $\left(\mathrm{F}_{7,103}=11.7, p<\right.$

1890.01 ; Fig. 1) and treatment $\left(\mathrm{F}_{1,103}=4.4, p=0.05\right.$; Fig. 1). The interaction term was significant

$190\left(\mathrm{~F}_{7,103}=9.6, p<0.001\right)$, with the increase evoked by LPS being greater than the increase evoked

191 by PBS, until 4 hours after injection. After this period, no difference was observed between the

192 net RMR of LPS and PBS injected bats ( $p>0.05$ for all pairwise comparisons).

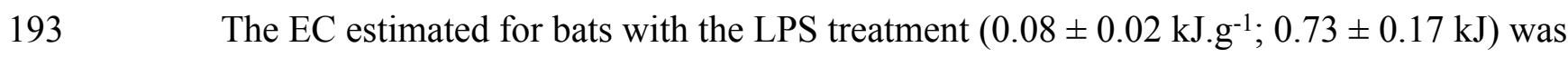

194 significantly different from zero $\left(\mathrm{t}_{6}=3.4, p=0.01\right)$, while the EC for the PBS group during the

195 same time period $\left(-0.01 \pm 0.02 \mathrm{~kJ}_{\mathrm{g}} \mathrm{g}^{-1} ;-0.13 \pm 0.08 \mathrm{~kJ}\right)$ was not $\left(\mathrm{t}_{5}=0.5 ; p=0.62\right)$. Mass-specific

196 EC was not affected by $\mathrm{T}_{\mathrm{a}}\left(\mathrm{LPS}: \mathrm{r}^{2}=0.02 ; \mathrm{F}_{1,6}=0.11 ; p=0.75\right.$. PBS: $\mathrm{r}^{2}=0.02 ; \mathrm{F}_{1,5}=0.09 ; p=$ 197 0.78).

\section{Discussion}

APR activation incurred an energetic cost for Glossophaga soricina as indicated by a

200 short-term decrease of body mass and an increased RMR. However, the increase of RMR after

201 LPS injection for this species was similar to the highest values measured in birds and it did not 
202 approximate that previously observed for the fish-eating Myotis.

203 Body mass loss $\left(\Delta \mathrm{M}_{\mathrm{b}}\right)$ of $G$. soricina challenged with LPS was nearly double that

204 observed for individuals challenged only with PBS. We found a 11\% decrease of body mass in

205 LPS challenged individuals of G. socirina after 8 hours, similar to changes reported for

206 piscivorous (M. vivesi: 8\% decrease 11 hours after injection; Otálora-Ardila et al., 2016) and

207 insectivorous bats (M. molossus: 7\% decrease 24 hours after injection; Stockmaier et al., 2015),

208 and the bird P. domesticus (7\% decrease 16 hours after injection; Bonneaud et al., 2003).

209 However, it was higher than mass changes reported for other birds and rodents including $M$.

210 musculus (no change 8 hours after injection; Baze, Hunter \& Hayes, 2011), T. guttata (1-3.5\%

211 decrease 24 hours after injection; Burness et al., 2010), Zonotrichia leucophrys (1-5.5\% decrease

21224 hours after injection; Owen-Ashley et al., 2008), Calidris canutus ( $<1 \%$ decrease 22 hours

213 after injection; Buehler et al., 2009) and R. norvegicus (4\% decrease 24 hours after injection;

214 MacDonald et al., 2012). Although some of the difference in the magnitude of $\Delta \mathrm{M}_{\mathrm{b}}$ probably

215 reflects differences in the dose used (see below) and in the time over which it was measured (8-

21624 hours), it mainly reflects the mobilization of nutrient stores to cover the energetic costs

217 associated with mounting an immune response and, thus, can be regarded as a universal

218 component associated with the APR in vertebrates (Ashley \& Wingfield, 2012).

219 Pre-injection RMR did not differ between G. soricina assigned to the LPS or PBS

220 treatments, but it decreased with time as expected; manipulation of bats before placing them in

221 the chamber usually leads to an elevated metabolic rate which decreases as bats settle down in

222 their new environment (Voigt \& Cruz-Neto, 2009). The average pre-injection RMR (pooled for

223 both treatments) measured during the first $\left(0.37 \mathrm{~kJ} \mathrm{~h}^{-1}\right)$ and second $\left(0.32 \mathrm{~kJ} \mathrm{~h}^{-1}\right)$ hours before

224 injection is consistent with basal metabolic rate measured for this species $\left(0.35 \mathrm{~kJ} \mathrm{~h}^{-1}\right.$, range: 
225 0.31-0.42 $\mathrm{kJ} \mathrm{h}^{-1}$; Cruz-Neto \& Abe, 1997). Mean RMR 1 hour after LPS injection increased by

$22663.2 \pm 12.8 \%$ with respect to the mean value before injection compared with $14.6 \pm 15.5 \%$ for

227 bats injected with PBS. However, this is difficult to interpret as the cost of mounting an immune

228 response as it is possible that bats entered torpor by bats after PBS injection which may have

229 overestimated the difference in RMR when compared with LPS-treated bats. Unfortunately, we

230 cannot further explore this hypothesis because we did not record $\mathrm{T}_{\mathrm{b}}$ but G. soricina enters diurnal

231 torpor only when food intake is restricted (Kelm \& Helversen, 2007). Food intake was not

232 limited the night before injections and thus we assume that bats remained normothermic during

233 the experiments.

234 There are a few studies in which RMR was measured for mammals and birds within 24

235 hours of LPS injection, and the results are quite diverse. Some studies reported no or minimal

236 increase in RMR (Baze, Hunter \& Hayes, 2011, M. musculus; Sköld-Chiriac et al., 2014, T.

237 guttata; Martin et al., 2017, P. domesticus), others reported increases in RMR of 10-14\%

238 (MacDonald et al., 2012, R. norvegicus; Burness, Armstrong \& Tilman-Schindel, T. guttata;

239 Martin et al., 2017 P. domesticus), and some reported increases of up to $26-40 \%$ (King \&

240 Swanson, 2013 and Martin et al., 2017, P. domesticus; Marais, Maloney \& Gray, 2011, Anas

241 platyrhynchos). For M. vivesi, RMR increased by $185 \%$ post-injection (Otálora-Ardila et al.,

242 2016). Unfortunately, results of these studies are not strictly comparable. For example, mass-

243 specific doses vary from 0.1 to $5 \mathrm{mg} \mathrm{LPS} \mathrm{kg}^{-1}$ in these studies. Although high doses seem to

244 elicit high responses (see also King \& Swanson, 2013), there are discrepancies with highly

245 variable responses both within and between species, even from the same batch and dose of LPS

246 (Demas et al., 2011; Martin et al., 2017). In addition, measurement of RMR was conducted at

247 different time periods after LPS injection and varying metrics used to calculate the effect on 
248 RMR compared to control or baseline data. Some studies use a fixed, and sometimes unique time

249 period for RMR measured, and assess the immune cost by dividing a single RMR value post

250 injection by RMR pre-injection, or by RMR measured at the same time after PBS injection.

251 We estimated the daily energy expenditure of $G$. soricina as $35.40 \pm 1.69 \mathrm{~kJ}^{\text {day }}{ }^{-1}$ using

252 an allometric equation derived from field metabolic rate data for bats $\left(\mathrm{kJ}^{\mathrm{day}}{ }^{-1}=5.73 \mathrm{M}_{\mathrm{b}}(\mathrm{g})^{0.79}\right.$;

253 Speakman \& Król, 2010) and the $\mathrm{M}_{\mathrm{bi}}$ of individuals treated with LPS. The total cost associate to

254 APR $(0.73 \mathrm{~kJ})$ represents $2 \%$ of the total daily energy expenditure of $G$. soricina. In contrast,

255 Otálora-Ardila et al. (2016) reported that the energetic cost of APR for the fish-eating Myotis

256 was $12 \%-15 \%$ of its daily energy expenditure. The overall mass-specific cost of the APR

257 response for G. soricina $\left(0.08 \mathrm{~kJ} \mathrm{~g}^{-1}\right)$ was less than one third of that estimated for the fish-eating 258 Myotis $\left(0.23 \mathrm{~kJ} \mathrm{~g}^{-1}\right)$.

Voigt, Kelm \& Visser (2006) calculated that G. commissarisi (mean $\mathrm{M}_{\mathrm{b}}=8.7 \mathrm{~g}$ )

260 consumes about $0.193 \mathrm{~kJ}$ per visit to a flower, and to cover its daily energy expenditure $(45.7 \mathrm{~kJ}$ 261 day $^{-1}$ ) it would need either to monopolize 26-90 plants or visit roughly 236 flowers per night. A

262 similar calculation for G. soricina suggests that this species would need to visit 183 flowers to

263 meet its daily energy expenditure. The energetic costs of APR would require G. soricina to

264 monopolize one additional plant or visit an additional 3-4 flowers. Even if we consider the

265 locomotory costs of visiting these additional flowers, it seems that the total costs associated with

266 APR for G. soricina are trivial and would not jeopardize its energy budget. However, APR

267 activation decreased food intake of other vertebrates (Aubert, Kelly \& Dantzer, 1997; Vallés et

268 al., 2000) and so there may be an additional negative impact on the foraging behavior of $G$.

269 soricina.

270 Conclusions 
271 The first direct measurements of the energy cost of APR activation in wild vertebrates were

272 made for birds and were higher than for laboratory rodents suggesting that this response is less

273 expensive for mammals (Marais, Maloney \& Gray, 2011). However, the large increase in RMR

274 recently measured for the fish-eating Myotis (Otálora-Ardila et al., 2016, 2017) and the results of

275 our study do not support this idea. The increase in RMR for the Pallas's long-tongued bat was

276 one third of the greatest increase measured in the fish-eating Myotis but significantly higher than

277 that measured for laboratory rodents and similar to the highest increase reported for birds. Our

278 finding suggests that, like other features of APR, its metabolic cost might vary among bats in

279 relation to ecological factors. Alternatively, body mass varies vastly among bat and mass might

280 influence the metabolic cost of APR activation. For example, both diet and body mass of several

281 species of bats were significantly related to leukocyte number, and bacterial killing ability

282 (BKA) decreases with increasing roost permanence (Schneeberger, Czirják \& Voigt, 2013b). In

283 addition, pace of life might also affect immune response as BKA is negatively correlated with

284 mass-adjusted basal metabolic rate (BMR) in birds (Tieleman et al., 2005). BMR in bats varies

285 with diet (McNab 2003; Cruz-Neto \& Jones, 2016) but its relation with immune response has not

286 been examined. Measurement of the energetic cost of immune response in wild mammals is in its

287 infancy and further work is warranted to evaluate its significance for the animal's energy budget.

288 Acknowledgments

289 Christine Cooper. Noah Ashley and two anonymous reviewers kindly improved the quality of

290 our manuscript.

291 References

292 Alexander C, Rietschel ET. 2001. Invited review: Bacterial lipopolysaccharides and innate

293 immunity. Journal of Endotoxin Research 7: 167-202. 
294 Allen LC, Turmelle AS, Mendonça MT, Navara KJ, Kunz TH, McCracken GF. 2009.

295 Roosting ecology and variation in adaptive and innate immune system function in the Brazilian

296 free-tailed bat (Tadarida brasiliensis). Journal of Comparative Physiology. B Biochemical

297 systemic and environmental physiology 179: 315-323.

298 Ashley NT, Wingfield JC. 2012. Sickness behavior in vertebrates: allostasis, life-history

299 modulation, and hormonal regulation. In: Demas GE, Nelson RJ, eds. Ecoimmunology. Oxford

300 University Press, Oxford. pp. 45-91.Aubert A, Kelley KW, Dantzer R. 1997. Differential effect

301 of lipopolysaccharide on food hoarding behavior and food consumption in rats. Brain, Behavior,

302 and Immunity, 11: 229-238.

303 Baker M.L, Schountz T, Wang LF. 2013. Antiviral immune responses of bats: a review.

304 Zoonoses and Public Health 60: 104-116.

305 Banet M. 1981. Fever and survival in the rat. Metabolic vesus temperature response.

306 Experientia 37: 1302-1304.

307 Baumann H, Gauldie J. 1994. The acute phase response. Immunology Today 15: 74-80.

308 Baze MM, Hunter K, Hayes JP. 2011. Chronic hypoxia stimulates an enhanced response

309 to immune challenge without evidence of an energetic tradeoff. The Journal of Experimental

310 Biology 214: 3255-3268.

311 Blatteis CM. 2003. Fever: pathological or physiological, injurious or beneficial? Journal of

312 Thermal Biology 28: 1-13.

313 Bonneaud C, Mazuc J, Gonzalez G, Haussy C, Chastel O, Faivre B, Sorci G. 2003. Assessing

314 the cost of mounting an immune response. The American Naturalist 161: 367-379.

315 Brook CE, Dobson AP. 2015. Bats as "special" reservoirs for emerging zoonotic pathogens.

316 Trends in Microbiology 23: 172-180. 
317 Buehler DM, Encinas-Viso F, Petit M, Vezina F, Tieleman BI, Piersma T. 2009. Limited access

318 to food and physiological trade-off $\mathrm{s}$ in a long distance migrant shorebird. II. Constitutive

319 immune function and the acute-phase response. Physiological and Biochemical Zoology 82: 561

$320-571$.

321 Burness G, Armstrong C, Fee T, Tilman-Schindel E. 2010. Is there an energetic-based trade-off

322 between thermoregulation and the acute phase response in zebra finches? The Journal of

323 Experimental Biology 213: 1386-1394.

324 Calisher CH, Childs JE, Field HE, Holmes KV, Schountz T. 2006. Bats: important reservoir

325 hosts of emerging viruses. Clinical Microbiology Reviews 19: 531-545.

326 Canale CI, Henry PY. 2011. Energetic costs of the immune response and torpor use in a primate.

327 Functional Ecology 25: 557-565.

328 Christe P, Arlettaz R, Vogel P. 2000. Variation in intensity of a parasitic mite (Spinturnix myoti)

329 in relation to the reproductive cycle and immunocompetence of its bat host (Myotis myotis).

330 Ecology Letters 3: 207-212.

331 Cray C, Zaias J, Altman NH. 2009. Acute Phase Response in Animals: A Review. Comparative

332 Medicine 59: 517-526.

333 Cruz-Neto AP, Abe AS. 1997. Taxa metabólica e termoregulação no morcego nectarívoro

334 Glossophaga soricina (Chiroptera, Phyllostomidae). Revista Brasileira de Biologia 57: 203-209.

335 Cruz-Neto AP, Jones KE. 2006. Exploring the evolution of the basal metabolic rate in

336 bats. In: Zubaid A, McCracken GF, Kunz TH, eds. Functional and evolutionary ecology of bats.

337 Oxford University Press, New York. pp. 58-69.

338 Demas GE, Zysling DA, Beechler BR, Muehlenbein MP, French SS. 2011. Beyond

339 phytohaemagglutinin: assessing vertebrate immune function across ecological contexts. Journal 
340 of Animal Ecology 80: 710-730.

341 Góes LGB, Campos ACA,Carvalho C, Ambar G, Queiroz LH, Cruz-Neto AP, Munir M,

342 Durigon EL. 2016. Genetic diversity of bats coronaviruses in the Atlantic Forest hotspot biome,

343 Brazil. Infection, Genetics and Evolution 44: 510-513.

344 Hasselquist D, Nilsson J-A. 2012. Physiological mechanisms mediating costs of immune

345 responses: what can we learn from studies of birds? Animal Behaviour 83:1303-1312.

346 Hegemann A, Matson KD, Both C, Tieleman BI. 2012. Immune function in a free-living bird

347 varies over the annual cycle, but seasonal patterns differ between years. Oecologia 170: 605-

348618.

349 Kelm DH, Von Helversen O. 2007. How to budget metabolic energy: torpor in a small

350 Neotropical mammal. Journal of Comparative Physiology B 177: 667-677.

351 King MO, Swanson DL. 2013. Activation of the immune system incurs energetic costs but

352 has no effect on the thermogenic performance of house sparrows during acute cold challenge.

353 The Journal of Experimental Biology 216: 2097-2102.

354 Kluger MJ, 1986. Fever: Is it beneficial? The Yale Journal of Biology and Medicine 59: 89-95.

355 Lee KA. 2006. Linking immune defenses and life history at the levels of the individual and the

356 species. Integrative and Comparative Biology 46: 1000-1015.

357 Lighton JRB. 2008. Measuring metabolic rates : a manual for scientists. Oxford University

358 Press, New York, 201 pp.

359 Lochmiller RL, Deerenberg C. 2000. Trade-offs in evolutionary immunology: just what is

360 the cost of immunity? Oikos 88: 87-98.

361 MacDonald L, Begg D, Weisinger RS, Kent S. 2012. Calorie restricted rats do not increase

362 metabolic rate post-LPS, but do seek out warmer ambient temperatures to behaviourally induce a 
363 fever. Physiology and Behavior 107: 762-772.

364 Marais M, Maloney SK, Gray DA. 2011. The metabolic cost of fever in Pekin ducks. Journal of

365 Thermal Biology 36: 116-120.

366 Martin LB, Kilvitis HJ, Brace AJ, Cooper L, Haussmann MF, Mutati A, Fasanello V, O'Brien S, 367 Ardia DR. 2017. Costs of immunity and their role in the range expansion of the house sparrow in

368 Kenya. The Journal of Experimental Biology 220: 2228-2235.

369 McNab BK. 2003. Standard energetics of phyllostomid bats: the inadequacies of phylogenetic$370 \quad$ corrected analyses. Comparative Biochemistry and Physiology A 135, 357-368.

371 Moratelli R, Calisher CH. 2015. Bats and zoonotic viruses: can we confidently link bats with 372 emerging deadly viruses? Memorias Do Instituto Oswaldo Cruz 110: 1-22.

373 O'Shea TJ, Cryan PM, Cunningham AA, Fooks AR, Hayman DYS, Luis AD, Peel AJ, Plowright 374 RK, Wood JLN. 2014. Bat flight and zoonotic viruses. Emerging Infectious Diseases 20: 741375745.

376 Otálora-Ardila A, Herrera M LG, Flores-Martínez JJ, Welch Jr KC. 2016. Metabolic cost of the 377 activation of immune response in the fish eating Myotis: the effects of inflammation and the 378 acute phase response. PLoS One 28 11: e0164938.

379 Otálora-Ardila A, Herrera M LG, Flores-Martínez JJ, Welch Jr KC. 2017. The effect of short380 term food restriction on the metabolic cost of the acute phase response in the fish-eating Myotis 381 (Myotis vivesi). Mammalian Biology 82: 41-47.

382 Owen-Ashley NT, Hasselquist D, Råberg L, Wingfield JC. 2008. Latitudinal variation of 383 immune defense and sickness behavior in the white-crowned sparrow (Zonotrichia leucophrys).

384 Brain, Behavior and Immunity 22: $614-625$.

385 Previtali MA, Ostfeld RS, Keesing F, Jolles AE, Hanselmann R, Martin LB. 2012. Relationship 
386 between pace of life and immune responses in wild rodents. Oikos 121: 1483-1492.

387 Schneeberger K, Czirják GA, Voigt CC. 2013a. Inflammatory challenge increases measures of

388 oxidative stress in a free-ranging, long-lived mammal. Journal of Experimental Biology 216:

$389 \quad 4514-4519$.

390 Schneeberger K, Czirják GA, Voigt CC. 2013b. Measures of the constitutive immune system are

391 linked to diet and roosting habits of Neotropical bats. PLOS ONE 8: e54023.

392 Schneeberger K, Czirják GA, Voigt CC. 2014. Frugivory is associated with low measures of

393 plasma oxidative stress and high antioxidant concentration in free-ranging bats.

394 Naturwissenschaften 101: 285-290.

395 Schountz T. 2014. Immunology of bats and their viruses: challenges and opportunities. Viruses

396 6: 4880-4901.

397 Sheldon BC, Verhulst S. 1996. Ecological immunology: costly parasite defences and trade-offs

398 in evolutionary ecology. Trends in Ecology and Evolution 11: 317e321.

399 Sikes RS, Gannon WL, The Animal Care and Use Commitee of the American Society of

400 Mammalogists. 2011. Guidelines of the American Society of Mammalogists for the use of wild

401 mammals in research. Journal of Mammalogy 92: 235-253.

402 Sköld-Chiriac S, Nord A, Nilsson JA, Hasselquist D. 2014. Physiological and behavioral

403 responses to an acute-phase response in zebra finches: immediate and short-term effects.

404 Physiological and Biochemical Zoology 87: 288-298.

405 Sköld-Chiriac S, Nord A, Tobler M, Nilsson JA, Hasselquist D. 2015. Body temperature changes

406 during simulated bacterial infection in a songbird: fever at night and hypothermia at day. The

407 Journal of Experimental Biology, 218: 2961-2969.

408 Speakman JR, Król E. 2010. Maximal heat dissipation capacity and hyperthermia risk: 
409 neglected key factors in the ecology of endotherms. Journal of Animal Ecology 79: 726-746.

410 Stockmaier S, Dechmann DKN, Page RA, O’Mara MT. 2015. No fever and leucocytosis in

411 response to a lipopolysaccharide challenge in an insectivorous bat. Biology Letters 11:

41220150576.

413 Strobel S, Becker NI, Encarnação JA. 2015. No short-term effect of handling and capture stress

414 on immune responses of bats assessed by bacterial killing assay. Mammalian Biology 80: $312-$ 415315.

416 Tai MM. 1994. A mathematical model for the determination of total area under glucose tolerance 417 and other metabolic curves. Diabetes Care 17: 152-154.

418 Tieleman BI., Williams JB., Ricklefs RE, Klasing KC. 2005. Constitutive innate immunity is a 419 component of the pace-of-life syndrome in tropical birds. Proceedings of the Royal Society of 420 London B: Biological Sciences 272: 1715-1720.

421 Vallès A, Martí O, García A, Armario A. 2000. Single exposure to stressors causes long-lasting, 422 stress-dependent reduction of food intake in rats. American Journal of Physiology-Regulatory, 423 Integrative and Comparative Physiology 279: R1138-R1144.

424 Voigt CC,Cruz-Neto AP. 2009. Energetic analysis. In: Kunz TH, Pearsons S, ed. Ecological and 425 behavioral methods for the study of bats. John Hopkins University Press, Baltimore. pp: 624426645.

427 Voigt CC, Kelm DH, Visser GH. 2006. Field metabolic rates of phytophagous bats: Do 428 pollination strategies of plants make life of nectar-feeders spin faster? Journal of Comparative 429 Physiology B 176: 213-222. 
430 Weise P, Czirják GA, Lindecke O, Bumrungsri S, Voigt CC. 2017. Simulated bacterial infection 431 disrupts the circadian fluctuation of immune cells in wrinkle-lipped bats (Chaerephon plicatus). 432 PeerJ 5: e3570.

433 Welch KC Jr, Herrera M LG, Suarez R. 2008. Dietary sugar as a direct fuel for flight in the 434 nectarivorous bat Glossophaga soricina. Journal of Experimental Biology 211: 310-316. 435 
Figure 1 (on next page)

Metabolic response of the Pallas's long-tongued bat Glossophaga soricina after LPS and PBS administration.

Resting metabolic rate of the Pallas's long-tongued bat Glossophaga soricina before and after LPS and PBS administration. Injection was administered at 0 minutes. 


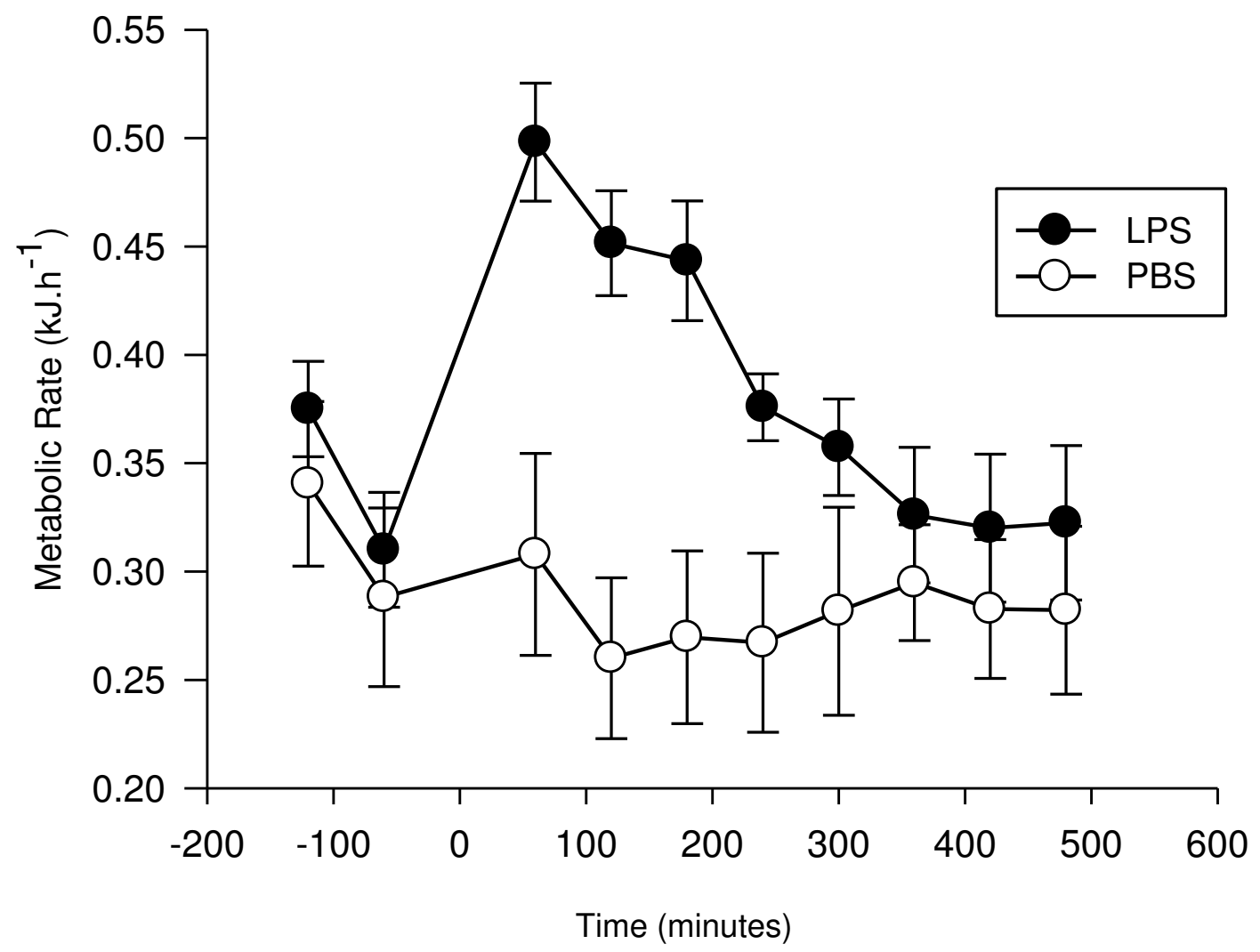




\section{Table $\mathbf{1}$ (on next page)}

Initial $\left(\mathrm{M}_{\mathrm{bi}}\right)$ and final $\left(\mathrm{M}_{\mathrm{bf}}\right)$ body mass of bats in the two treatment groups (LPS or PBS).

$M_{b}$ values are in grams. $A D=$ absolute difference $\left(M_{b f}-M_{b i}\right)$ and relative difference $\left[\left(M_{b f}-\right.\right.$ $\left.M_{b i} / M_{b i}\right]$. Values are presented as mean \pm 1 . s.e.m. Numbers in parenthesis denote range of observations. 


\begin{tabular}{ccccc}
\hline Treatment & $\mathrm{M}_{\mathrm{bi}}$ & $\mathrm{M}_{\mathrm{bf}}$ & $\mathrm{AD}$ & $\mathrm{RD}$ \\
& & & & \\
LPS & $10.05 \pm 0.62$ & $8.90 \pm 0.50$ & $-1.15 \pm 0.14$ & $-0.11 \pm 0.01$ \\
$(\mathrm{n}=7)$ & $(8.6-13.2)$ & $(7.8-11.6)$ & $(-0.60--1.62)$ & $(-0.07--0.15)$ \\
& & & & \\
& & & & \\
PBS & $10.61 \pm 0.62$ & $10.01 \pm 0.66$ & $-0.60 \pm 0.11$ & $-0.06 \pm 0.01$ \\
$(\mathrm{n}=6)$ & $(8.8-12.8)$ & $(7.9-12.0)$ & $(-0.30--0.90)$ & $(-0.03--0.10)$ \\
& & & & \\
& & & & \\
\hline
\end{tabular}

